\title{
Erratum of "Role of CEACAM1, ECM, and Mesenchymal Stem Cells in an Orthotopic Model of Human Breast Cancer"
}

\author{
Sridhar Samineni, ${ }^{1,2}$ Carlotta Glackin, ${ }^{3}$ and John E. Shively ${ }^{2}$ \\ ${ }^{1}$ Irell \& Manella Graduate School of Biological Sciences, City of Hope, Duarte, CA 91010, USA \\ ${ }^{2}$ Department of Immunology, Beckman Research Institute, City of Hope, Duarte, CA 91010, USA \\ ${ }^{3}$ Department of Neurosciences, Beckman Research Institute, City of Hope, Duarte, CA 91010, USA \\ Correspondence should be addressed to John E. Shively, jshively@coh.org \\ Received 1 December 2010; Accepted 13 December 2010
}

Copyright (C) 2011 Sridhar Samineni et al. This is an open access article distributed under the Creative Commons Attribution License, which permits unrestricted use, distribution, and reproduction in any medium, provided the original work is properly cited.

In the paper by Samineni et al. [1], the following corrections should be made: (1) page 3 column 2 line 18 should read "Figure 1(c)," (2) page 3 column 2 line 24 should read: "Figure 1(b)," (3) Figure 2 should be replaced with the attached new Figure 2. The figure legend remains the same.

\section{References}

[1] S. Samineni, C. Glackin, and J. E. Shively, "Role of CEACAM1, ECM, and mesenchymal stem cells in an orthotopic model of human breast cancer," International Journal of Breast Cancer, vol. 2011, Article ID 381080, 10 pages, 2011. 


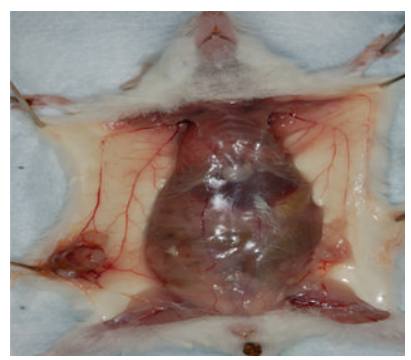

(a)
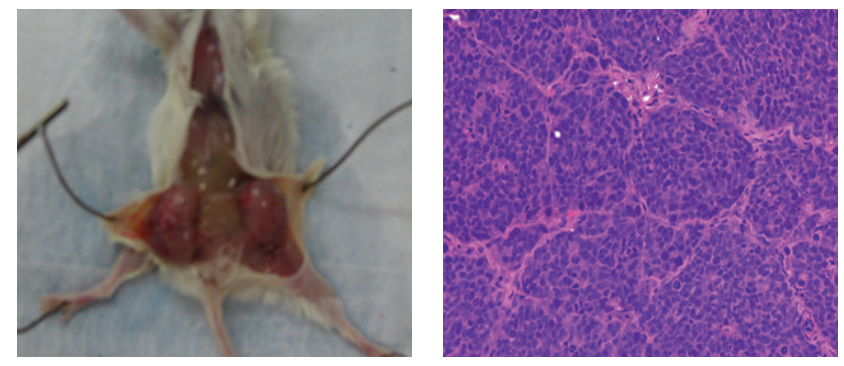

(c)
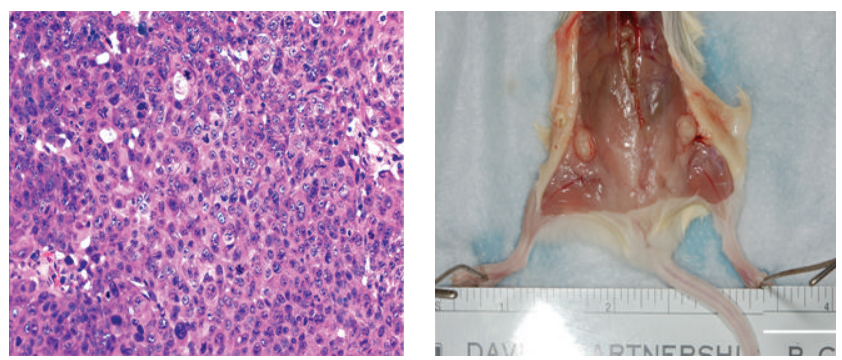

(b)
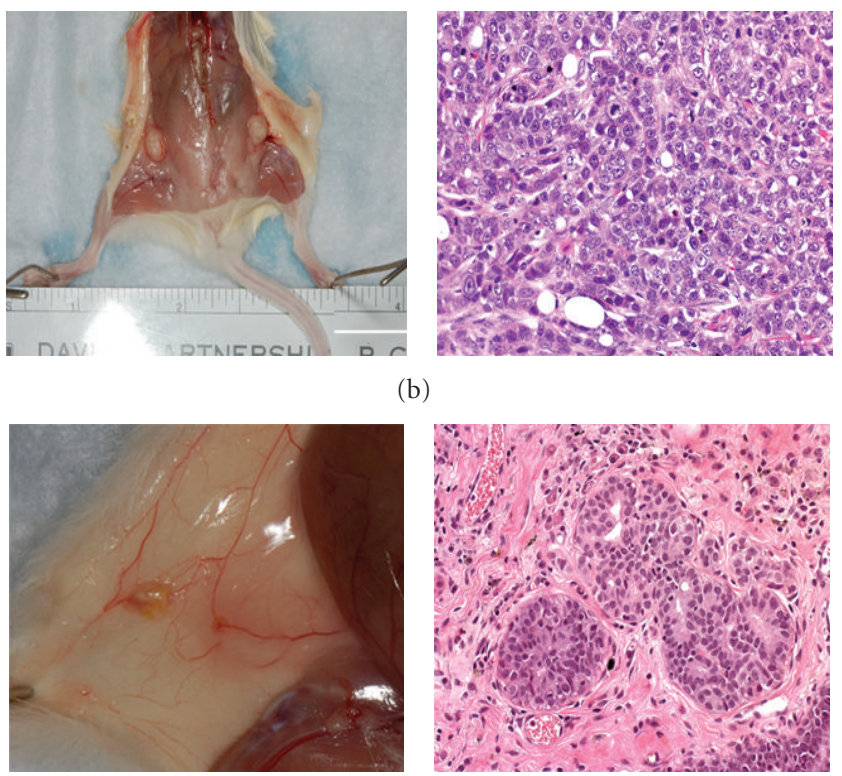

(d)
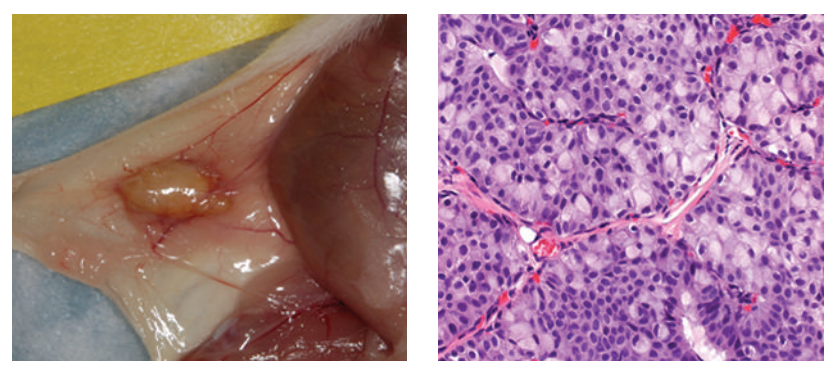

(e)

FIGURE 2: Growth and formation of xenografts by commonly used breast cancer cell lines or human breast tumor tissue in nascent mammary fat pad of NOD/SCID mice. Gross pictures of human xenografts (left panels) and corresponding H\&E stained sections of xenografts (right panels) from breast cancer cell lines or human breast tissue implantation (a) SUM1315, (b) MDA-MB-468, (c) DU4475 (magnification 200x), (d) human breast epithelial organoids (magnification 400x), and (e) human breast tumor slices (magnification 200x). 


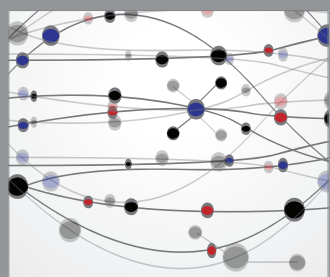

The Scientific World Journal
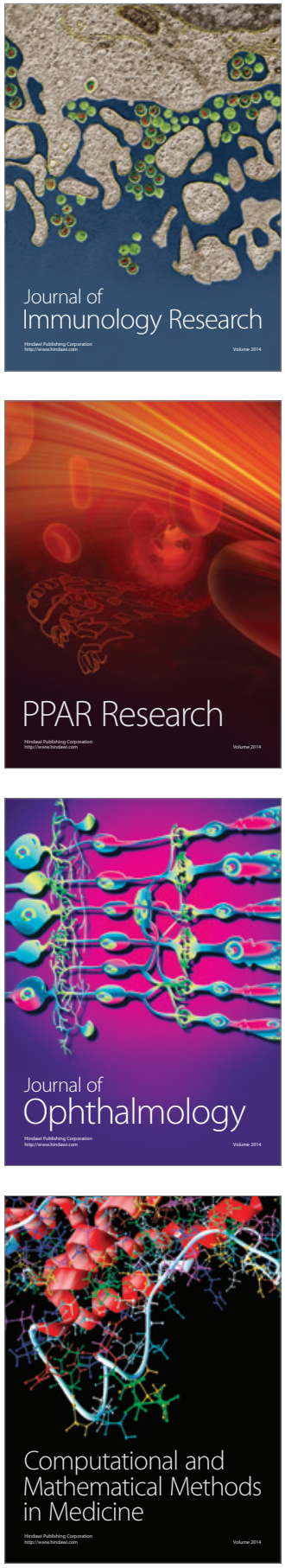

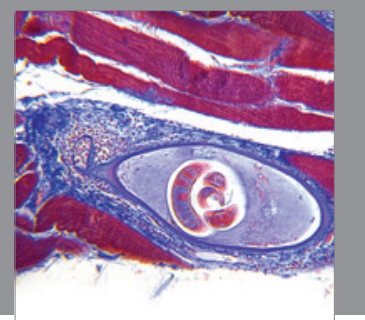

Gastroenterology

Research and Practice
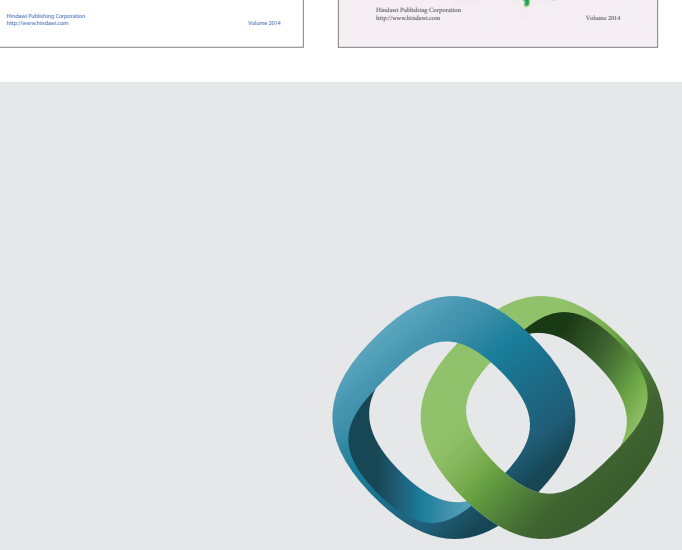

\section{Hindawi}

Submit your manuscripts at

http://www.hindawi.com
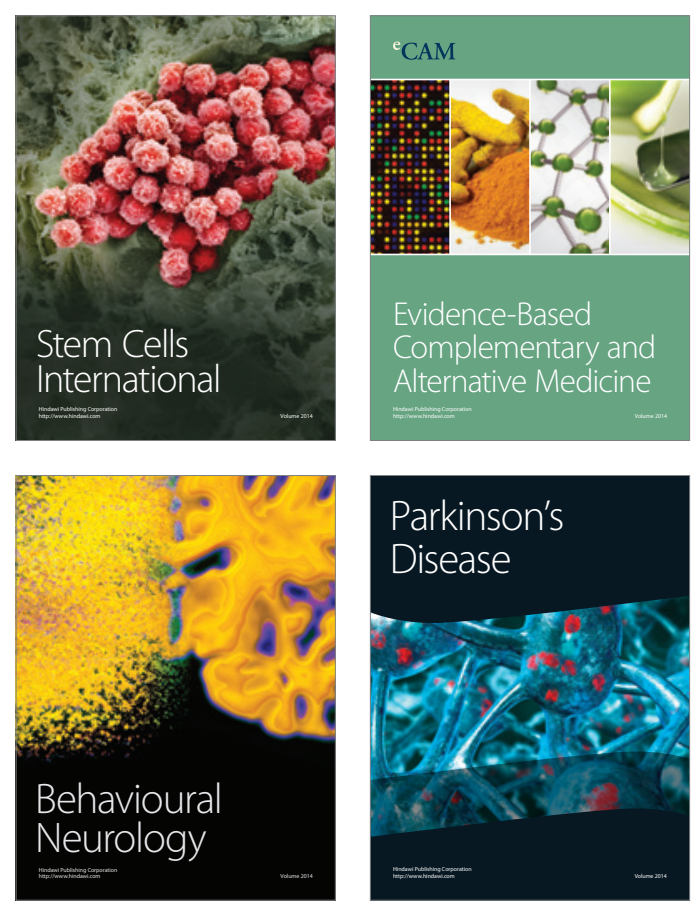

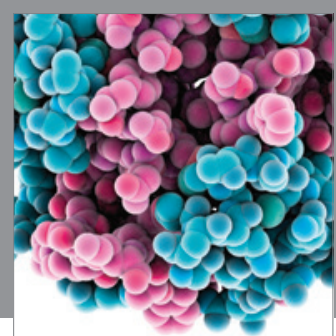

Journal of
Diabetes Research

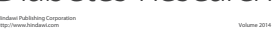

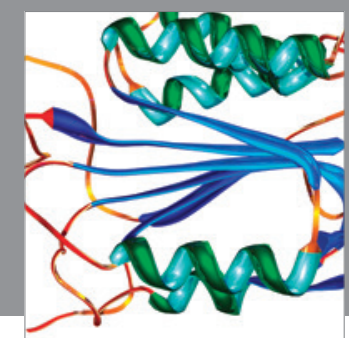

Disease Markers
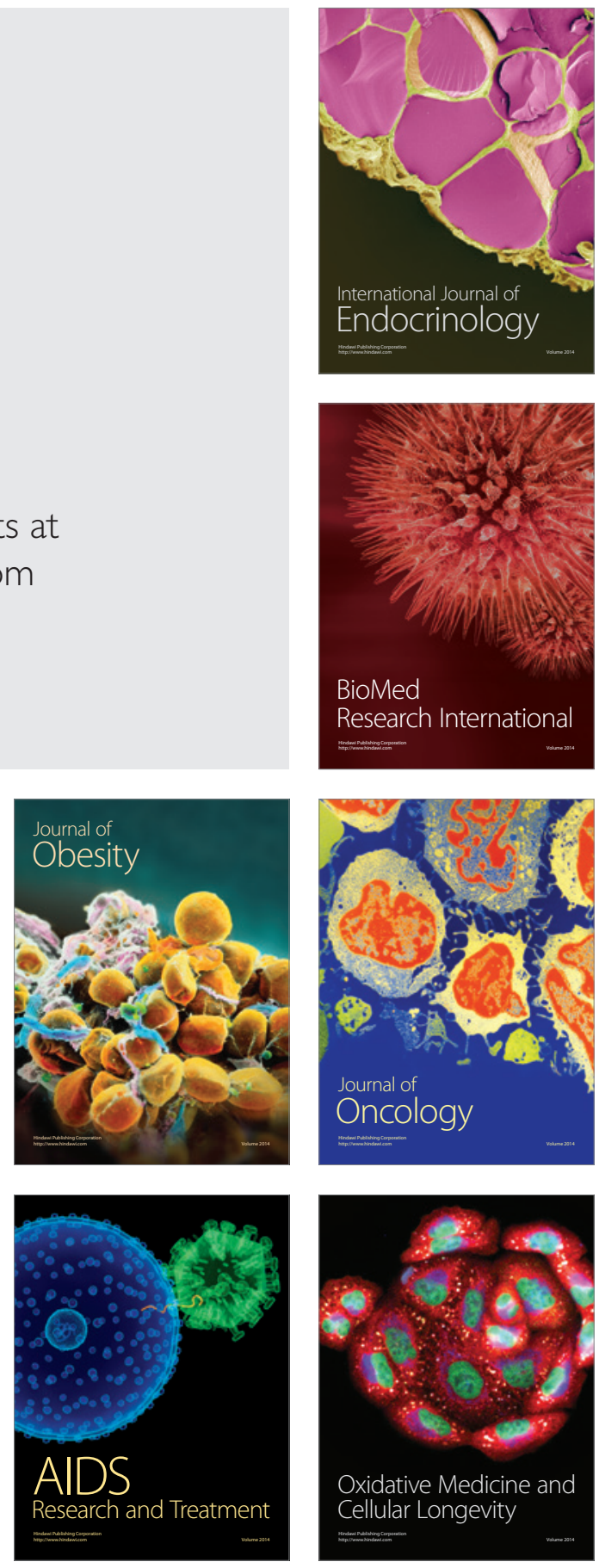